\section{AN INAUGURAL ADDRESS}

\author{
oN
}

\section{THE PROPER OBJECTS AND NECESSARY LIMITATIONS OF MEDICAL EDUCATION.}

Delivered at the Opening of the Winter Session of the Nottingham Medico-Chirurgical Society on October 4th, 1899.

BY ROBERT SAUNDBY, M.D., LL.D., F.R.C.P., Professor of Medicine, Mason University College, Birmingham.

I APPRECIATE from the bottom of my heart the compliment you have paid me by inviting me to open your winter session, but the pleasure I feel is alloyed by many considerations. I cannot but ask myself what qualifications I possess to justify me in accepting this honourable office, and finding no sufficient answer from my self-examination, I am obliged to leave with you the responsibility for your choice, and to trust that you will credit me with doing my best to serve you should you not derive all the pleasure and profit you expect from wnat $I$ have to say here to-night.

Upon these occasions nothing gives the orator of the evening more anxiety than the choice of his subject. By far the most easy theme is some department of practical medicine to which he may have happened to give special attention, but in spite of its advantages there are obvious objections to this course, and therefore I have decided to direct your attention to a matter.in which, as members of the great corporation of medicine, we are all interested, but which comes home especially, not only to those who are engaged in teaching, but to all who have sons entering or about to enter upon their medical studies.

During the century which is drawing so near its end, great and in fact fundamental changes have taken place in the method of medical education in England, and although some of the alterations are of recent date, we may reckon that for the last forty years the new system has prevailed, and that it is not too early to review the results achieved, and to attempt to appreciate how far the movement has been in the right direction, to what extent the main objects have been kept in sight, and whether we may safely leave matters to develop along the lines in which they seem to have settled, or whether fresh efforts may be needed to bring our educational system into better relation with the requirements of the times.

The great departure from the old to the new, which I date approximately as having occurred forty years ago, was the abandonment of apprenticeship and the transfer of medical education from the surgery of the general practitioner to the universities and hospital schools.

We are accustomed to hear very severe things said of the old apprenticeship system, and I do not think it would have been given up if it had not had serious faults, but it still has its advocates who allege in its favour that it provided a kind of training which has little or no place in modern medical educational schemes.

This controversy is interesting because the contending parties represent the two sides of medical education, each of which contains much that is good, much that is essential, and which it is and has been the object of medical educationists to endeavour to combine.

A passage taken from the Life of Thomas Wakley admirably describes the state of medical education in England, so far as the general mass of the profession was concerned, during the first half of the present century: "A large proportion of the medical men in the country were what nowadays would be termed ' unqualified.' They possessed qualifications to practise, certainly ; for example, they had generally served severa years of apprenticeship to men grown grey in the pursuit of the healing art, and they were mostly sound obstetricians, expert prescribers, and;accurate dispensers, but of all standing derived from the successful endurance of the tests of examination they were guiltless."

It is possible that this passage errs on the side of generosity, but while allowing them to have been " expert prescribers" it says nothing about their skill as diagnosticians; yet need we not readily believe that the men of those days were deficient in practical bedside knowledge. With \& very limited nosology, without any practical knowledge of morbid anatomy, without the clinical thermometer, little acquainted with clinical chemistry or with auscultation, trusting to the pulse, the skin, the tongue, and the mere inspection of excreta for the indications of disease, they were at enormous disadvantage compared with the men who began to be turned out of the schools fully equipped with the new methods derived from the teaching of Laënnec and Bright.

The persistent advancea made by scientific medicine since that time, the extension of our knowledge of pathology, the invention of new instruments for clinical research, and the constant improvements in methods of treatment, have united to make it out of the question for the apprenticeship system to compete with the teaching of the schools. The enormous advantages of the modern hospital system, in which every means is employed to improve the practice of our art; the development of specialization by which an extraordinary amount of attention is devoted to each department of practice; the remarkable precision in diagnosis and skill in treatment of particular diseases thereby attained, have rendered it hopeless for the general practitioner to hold his ground as a teacher.

But the advocates of apprenticeship do not ask that it. should take the place of time spent in a medical school. If it. is not to do this, it must be precedent or concurrent. If precedent, it may be said to interfere with general education. If concurrent, it must be only in the last three years of the curriculum that any new scheme of [apprenticeship can find its place.

\section{Preuiminary Edocation.}

Before the enormous advance began which has characterised the present century, it was not altogether unreasonable to. regard the profession of medicine as one which required little preliminary education, and for which a practical training would suffice, but when physiology and pathology had grown into formidable dimensions, and their bearings upon practical questions could be no longer gainsaid preliminary education became of greater importance.

We cannot pretend that we have yet settled satisfactorily what amount of evidence shall be required of preliminary studies. It is certain that it is still possible to become registered as a medical student with very little knowledge of English grammar and spelling, and with the most imperfect acquaintance with other branches of polite learning.

Professor Jebb has summarised the reasons given by the Berlin Philosophical Faculty for retaining classical education as a training for professional studies:

1. Ignorance of Latin and Greek is a positive obstruction to the pursuit of many branches of study.

2. The ideality of the scientific sense is cultivated by studies which have not an immediate bearing upon daily life.

3. An interest in knowledge for its own sake is promoted by them.

4. The power of thinking receivesła varied general exercisein these studies.

5. They are of historical value as illustrating the founda-. tions on which so much of modern thought and life has been built.

These reasons may not appear to be very forcible in their application to the general run of students who are not likely to become more than practitioners, and reasons 2,3 , and 4 would apply equally to mathematics, while the others are much diminished in importance when we reflect that good translations exist of every work which the average student would desire to study. Acquaintance with French and German would probably help him much more in extending his professional knowledge atter he has taken his degree.

But our system of secondary education in England is so firmly rooted in classical studies that any change is attended with great and grave difficulties. For the training of the boyish intellect it is of more importance to teach one thing pretty thoroughly than to consider what that thing shall be, and as our public schools appear to be capable of teaching Latin and Greek only with any degree of thoroughness we must accept them as the educational groundwork.

But if this is to be our conclusion ought we not to exact 
frcm our can lidates a higher standard than at present they exhioit or should we adopt two standards, namely, a university standard for those who aspire to the best professional education, and another permitting access only to a modified course in which throughout the examination tests should be less exacting, the end in view being the training of men to fill the ranks of ordinary practitioners?

This division of the profession into higher and lower strata actually exists in England, but is made the object of constant attack on the part of those who resent any mark of inferiority. In France and Germany the inferior grade also exists in law, but not in fact, no candidates having come forward of late years for the lower qualitications.

We must therefore recognise that the tendencr of the age is towards the obliteration of these distinctions. The cry for "one portal" is the expression of the democratic longing for uniformity whether by levelling up or by levelling down. In this instance it is probable that those who cry out do not want to level down, but it is practically impossible to bring the general standard higher than the level of average attainments. If this were done there would be a deficiency in the supply of qualified men and a forcible lowering of the standard would result in the end.

The proper standard for the preliminary examination is that attained by average boys on leaving our public or grammar schools at the age of 18 . There should be no difficulty in getting schoolmasters to determine what this is. If our public schools would take a lesson from Germany and hold "leaving examinations," such certificates would become the best passport to the special studies required for the learned professions. The present standard, which is that of a boy of 14 is fur too low. It is to be hoped that the General Medical Council, which has submitted the consideration of this subject to a committee, wiH introduce a real reform. the basis of which should be the attainment of the standard of the average boy leaving a public or grammar school at the age of 18 . Upon this principle no subjects should be made compulsory which do not form a necessary part of the education given in such schools, for to do so is to encourage cramming, and can serve no useful purpose either as a test or as education. I am very sorry that this view, which seems to me so indisputable, is far from being generally accepted. Only a few months ago I served upon a committee engaged in drawing up the Regulations for Graduation in Medicine in the future university of Birmingham, and for the reasons given I objected to the inclusion of mechanics in the medical preliminary examination. The answer which prevailed against me was that medical students ought to know mechanics, and that arrangements cjuld not be made for teaching this subject as part of the medical curriculum. It seems to me that there is scarcely any subject which might not be included by similar reasoning, and that there is less to be said for mechanics than, for exzmple, for German. The object of the preliminary examination should be to test the previous education of the student, and the examination itself ought to be limited by the conditions of education as they exist in the secondary schools of this country.

Preliminary Science.

After the medical aspirant has successfully surmounted the barrier of the preliminary examination, and has been admitted to the register of medical students, he should enter at once upon his medical studies.

It is not assuming too much if we suppose that the subjects set before him should be those and those only which are necessary for his equipment as an accomplished medical practitioner; but the designers of medical education have taken a singularly broad view of what is needful. In no other profession is the student asked to acquire a knowledge of half a dozen preliminary sciences before being allowed to attack the subject matter of the profession which he hopes one day to practise. Is an engineer made to learn geology, metallurgy, and chemistry, or a lawyer to study sociology and political economy, or a clergyman theory of nusic, and principles of ecclesiastical law, architecture and arihæology? The value of such studies may be freely adin tted, and all may be willing to grant that breadth of cul1. re benefits all professions, but in framing a scheme of prof. * ional education only those subjects should be insisted $u_{l}$ on wh ch are essential in practice.
There will always be some men possessed of more time and money, or impelled by thirst for knowledge, who will extend their education beyond the prescribed limits, and as the better educated men probably reach the most eminent positions in life, there will be inducement enough for it to be quite safe to leave such studies to take care of themselves.

At present the average student regards these subjects without interest, he acquires just so much as may enable him to satisfy the examiners and then dismisses them from his mind. There is no real grasp of principles, and the process is without any educational value, the thin varnish of scientific knowledge being sloughed off completely like a snake's skin. The actual courses of study are too brief, the opportunities for practical work too limited, the examination standard too low, and the whole scheme of scientific study too superficial to be anything but a shan and make-believe.

Botany, geology, chemistry, and physics will be ultimately removed altogether from the medical curriculum as compulsory subjects. In the universities every facility should be provided for teaching these subjects to those students who are able to afford to devote two years to purely scientific studies before commencing their strictly professional education. Such a change would not alter the value of these subjects, but they would rest solely upon their merits. We may believe such il scientific training to be an excellent thing when properly acquired, greatly adorning its possessor, and bearing fruit of the richest sort, but yet be unconvinced that the time now spent by the average Conjoint Board student upon science subjects produces anything to justify the system. If these subjects were of the importance which it seems to be an article of faith to maintain they would not be so soon 'forgotten, and that they are generally forgotten everyone who has had to do with the teaching and examining of senior students must admit.

Mr. Teale has suggested that such subjects should be excluded from the examinations but still taught in the schools. This would be very unsatisfactory, as unless attendance were compulsory the classes in smaller schools would be neglected, and the teachers discouraged, and if compulsory it would be for the greater part of the men sheer waste of time.

If the preliminary examination were confined to its proper functions as a test of the educational fitness of candidates for professional studies, and if the science part of the curriculum were struck out entirely so that these would become only optional subjects, the student who desired to enter directly upon his professional work would be in a very much better position than at present. He would begin anatomy and physiology at once, and would be able to devote all his time to them, without a thought of anything intervening as at present.

Anatomy is, and ought to be, the scientific basis of medical education. It has the enormous advantage from an educational point of view that it consists of a fixed series of precise data not so extensive as to require other than its natural limitations, whilst it keeps everywhere in touch with the whole superstructure of medical knowledge. Further, it can be taught throughout in the best possible way, by personal investigation; and each student may-and in fact doesverify for himself most, if not all, of the details he has to commit to memory. It therefore possesses all that is wanted as an intellectual scientific training, and is calculated to steady the mind and produce the best type of medical practitioner.

If anatomy deserves our thorough confidence and respect, and must be regarded as the very central pillar of medical education, its sister science physiology, stands in a very different position.

Physiology, as taught to medical students, should be confined to well-digested doctrines, demonstrable by experiment and as far as possible demonstrated to the class. It should be the complement to anatom in teaching the functions and mechanism of the apparatus whose structure is revealed by the latter.

But the great facts of physiology--the discoveries of Harvey, Hunter, Charles Bell, Cl. Bernard, giants whose names will stand for ever as the founders of scientific medicine-nowadays run a risk of being buried under an indescribable accumulation of so-called researches, which contradict one 
another and themselves and are constantly changing the surface of things. This, it may be said, is an unavoidable condition of progress in a science dealing with vital phenomena, but the explanation, even if satisfactory, leaves it still more than doubtful whether a science which is constantly changing its data can be a good intellectual training for students.

Physiology compares unfavourably with anatomy, not only by the absence of finality. in its doctrines, but in the want of relation too often existing between the details upon which teachers and examiners insist the most and the practice of medicine.

Admitting that it is impossible to foresee the ultimate bearing of a given scientific research, would it not be better to omit those points from class teaching which are either still unsettled or of doubtful application? If this rule were followed students of physiology would have great and muchneeded relief. Finally, the subject cannot be worked out by the student himself to the same extent as is possible in anatomy; and although there is a very general recognition of the importance of personal laboratory work, there is considerable room for improvement in the arrangements made for it, especially in the matter of supervision and the help afforded to students thus engaged.

To sum up this criticism, the teaching of physiology should be limited to what is definitely known, and to what is applicable to medical studies; practical work should be better corganised, extended, and more efficiently supervised.

Hospital Attendance in First and Second Years.

Ought the student to go to hospital while he is working at anatomy and physiology? As it is impossible to acquire a proper knowledge of these subjects in less than two years, such a contention seems impracticable, but it is also inconsistent with a sound conception of professional education which should never lose sight of the paramount importance of bringing the student as early as possible face to face with the practical realities of his professional work.

I confess that there is a great deal of time wasted about hospitals, and that the attendance at them of students might be much better organised than it very often is. In the case of junior students especially there should be no waiting about. Classes for first and second years' men should be arranged in the shape of demonstrations of clinical cases by bringing patients one by one into a room and pointing out their chief features, a method of teaching which is of the highest utility and is far too little employed. Attendance twice a week for an hour a day at such case demonstrations would be sufficient for first year's men, but the second year's men should also attend twice a week at post-mortem examinations or demonstrations of recent specimens of morbid anatomy. By these means the minds of students become early familiarised with the aspect of a great many of the subjects which they will be later on called to study more closely, and they insensibly acquire the groundwork of a practical education which consists, above all, in daily familiarity with its subject matter.

\section{Practical Subjects.}

When anatomy and physiology have been mastered the foundations of medical education have been securely laid. The student has now to be taught medicine, surgery, and obstetrics, and we have to consider how these can best be taught, and how much of all that is included in them shall be attempted in the three years remaining of the curriculum.

Let us enumerate the subjects of which the student is expected to learn more or less, and review the means of instruction afforded him by the present system. He is in the first place expected to learn the symptoms, pathology, and treatment of about five hundred diseases included under the heading of medicine, of about as many more under surgery, to know the mechanism of normal and abnormal parturition, and the diseases incident to that state and the other special diseases of women; to acquire some knowledge of lunacy, diseases of the eye, ear, throat, and skin, of venereal diseases; to become acquainted with all the drugs in the Pharmacopocia, their composition, uses, and doses ; to practise dispensing medicines; to perform surgical and obstetric operations; to dress wounds; to learn the clinical use of the stethoscope, ophthalmoscope, laryngoscope, and microscope ; tc test urine, to examine blood, to make post-mortem examinations; and to familiarise himself as far as possible with diseases of all kinds by attendance on practice in the wards and the outpatient rooms of the hospital. In addition he must devote some of his time to the study of the principles of medical jurisprudence, the rules of public health, and the practice of vaccination.

This formidable list is not at all exaggerated, and might easily be extended. It appears appalling when set out in this way, and one ceases to wonder at the difficulties students find in satisfying their examiners.

The means used to convey as much as possible of this tremendous total are in the first place systematic lectures. The course of medicine takes two years and even in that time it is difficult to deal adequately with the subject. Surgery takes as long. Pathology and bacteriology, systematic and practical, form at least sufficient for one winter and one summer course. Obstetrics, gynæcology, lunacy, ophthalmology, materia medica, therapeutics, medical jurisprudence, public health, operative surgery, and operative midwifery are taught in as many three months' courses, ten in all. The methods of medical examination and the use of clinical instruments of research, urine testing, the dressing of wounds, putting up fractures, the use of surgical instruments, dispensing, the performance of post-mortem examinations, and practical midwifery are taught at the hospital, or at least the student has opportunities of learning them there with more or less supervision. The diagnosis and treatment of disease are also taught in clinical lectures, in ward classes, and in the practice of the wards, the operating theatres, and the outpatient rooms.

All our hospitals have, in addition, to the wards devoted to medical and surgical cases, special departments with or without beds for obstetrics, gynæcology, diseases of the eye, the ear and throat, and the skin. Each of these departments is in charge of one or two specialists.

Students are compelled to serve for varying periods as ward clerk, surgical dresser, and post-mortem room assistant, to attend personally a certain number of cases of labour and to dispense medicines, but the whole of this compulsory service does not occupy more than eighteen months out of three years, and for the remainder of the time the student attends pretty much as he pleases upon the practice of the hospital.

There is no regulated proportion between the number of students and the size of the hospital, so that in the most popular schools there is a good deal of crowding and the less able or less energetic students suffer. This is partly compensated for by the better tone of these schools, where the competition begets a keenness of interest that is sometimes lacking where the opportunities for everybody are abundant.

The special hospitals, which possess most valuable material for clinical teaching, are scarcely made use of at all for teaching purposes.

The systematic and practical College classes occupy as much time as can be spared from the hospital during at least two of the three years. Materia medica has lately been taken earlier in order to relieve the pressure upon this period.

The Advantages and Disadjantages of Systhmatic LECTURES.

When books were scarce and very dear, systematic lectures were absolutely necessary, and the professorial chair was for the student almost the sole available source of knowledge, but the abundance and cheapness of moaern publications have so altered matters that the justification of their continuance is not easy. An advocate for them may urge: (1) that they offer a careful digest and selected summary of the subject; (2) that oral instruction impresses itself strongly upon the memory; (3) that the mind of the student is aided by the personality of the teacher, his voice and gestures; and (4) that the lesson is illustrated by examples, drawings, and museum specimens.

Yet they are notoriously unpopular and neglected, few students attending with perfect regularity; and it must be confessed that the gift of lecturing is not possessed by all the occupants of our chairs. The lectures themselves are often diffuse essays read from manuscript, without art or charm of style or voice, and illustrations are neglected. Moreover, all our subjects grow year by year more unwieldy. If science is 
an arranged description of facts, and if these facts are being annually added to, as time goes on the lecturer must find himself less able to deal adequately with his subject in the time allotted to him. If he limits himself so as to treat fully of certain parts which he deems of greatest importance, his course becomes incomplete, while if, on the other hand, he aims at comprehensiveness, he must omit many details, and be open to the charge of superficiality. No one seems to be prepared to increase the number of lectures, yet unless this is done they must become still more discredited as full and fair presentations of their subject matter.

Great and powerful interests are no doubt involved in the maintenance of the principal chairs, but it seems inevitable that they will in time pass away or be largely modified. It is probable that less formal conferences upon cases and specimens will ultimately take the place of systematic lectures.

\section{Practical Crasses.}

During the past twenty-five or thirty years there has been a marked tendency to supplement systematic lectures by practical classes conducted by tutors or class assistants, and without doubt these constitute a most valuable feature in modern medical education. Auscultation and percussion, the use of the laryngoscope and ophthalmoscope, bandaging, and the treatment of fractures, minor and major surgical operations, urine testing, operative midwifery, morbid anatomy, bacteriology, and pharmacology are taught in small classes, which are provided with all the needful appliances. Our schools are competing with one another by extending their laboratory accommodation and multiplying their assistant staffs, thus showing plainly the direction in which medical education is tending. This movement deserves every encouragement, and in spite of opposition from vested interests from conservatism, from apathy, from want of money, and from insufficient structural accommodation, its steady progress shows that it is fulfilling the requirements of the times.

Hospital Teaching.

The most important and most essential part of professional education must be that in which the student is trained and practised in his work by watching or assisting experienced masters, and performing personally under their supervision the varied duties which he will be required to do when he comes to prartise his profession. Medical education must have for its object to form medical practitioners who will be able to recognise a case of pneumonia, pass a catheter, apply forceps, put up a fracture, or dress a cut head. Knowledge of anatomy, physiology, and pathology is barren, and avails nothing if this end is not attained. As already indicated, under the old order of things medical practitioners were not expected to be able to do much, and if the above enumeration represented the extent of the requirements of modern practice a country surgery would often afford sufficient opportunities for practical medical education. Skilled special advice, consultants of all sorts are becoming every year nore accessible so that the general practitioner is not thrown so much as formerly upon his own unaided resources, and it would not be impossible to sketch out a course of practical instruction which would be more useful for the training of a general practitioner than the present system, which aims at universal knowledge, and is constantly becoming larger and more complex by the growth of old specialities and the splitting off of new ones. The only limitations to this process seem to be time and the capacity of the human brain. It is now impossible for a student to acquire an adequate knowledge of each of the specialities of medicine and surgery, but if the specialists had their way each would be made the subject of a three or six months' course of study, with a special examination to be conducted by specialists. However, as I propose to say a few words about examinations later on, all that need be said here is that it is to be feared that the course of practical study is more strictly determined by the requirements of the examining Boards than by those of practice, or, to put it another way, that the examinations and the requirements of practice are not so completely in harmony as might be thought desirable.

The plans followed in hospitals differ so much that it is not possible to describe except in brozd outline the course of instruction which the student rcceives. As a rule, the work of a hospital is chiefly carried on in the morning or in the aiternoon, and occupies two to three hours of the day. This work consists in ward visits, out-patient practice, surgical operations, post-mortem examinations, clinical lectures, and tutorial classes. Many of these must be going on at the sametime, and unless the work of the student is mapped out for him he is likely to get little benefit from desultory attendance upon so many things.

\section{Clinical Lectures.}

The ideal clinical lecture is that which is conducted in a well-lighted theatre, into the arena of which one or more patients illustrating a particular disease or group of diseases is introduced, and the case of each in turn thoroughly described and commented upon. But apart from the fact that many cases, especially medical cases, are not easily brought. into the theatre, and when there show little that can be appreciated by a seated class, such lectures require some preparation and previous thought. I find teachers disposed to shirk them, or to substitute for them a systematic lecture or a ward visit. They are, perhaps, most needed in crowded schools with large classes, but if done well they are most. valuable as a means of instruction. They should be as much clinical demonstrations as possible, and should have as little as possible of the lecture character, in other words, they should be shows not sermons. With a little more organisation it would be possible to improve this part of our teaching very much. On each clinical lecture day, not one member only, but. each member of the medical staff on medical days, or surgical staff on surgical days, should be invited to present a case. An exhibition of cases for junior students might be supplied from the out-patient department by the assistant physicians and assistant surgeons, both medical and surgical patients being shown on the same day, those cases being selected which present well-marked objective signs. No doubt to arrange such demonstrations would involve some trouble, but we see how well they are managed at the London Post-Graduate College and at several of the hospitals where post-graduate instruction is given, which point the way to a decided improvement in our present system of hospital instruction for students.

WaRd VISITS.

In the ward visit students have the opportunity of seeing a greater variety of cases, but the opportunities for learning and the instruction afforded vary greatly. Many of us have followed among a crowd of fifty students, of whom only a few could see or hear anything; but in small schools, where the visiting staff take pains to teach, the ward visits are extremely useful. Where the notes of the case are read over, and all its features demonstrated, opportunity being given as far as possible to the students to verify the observations for themselves, the form of instruction cannot well be improved.

It is to be regretted that students do not see the advantage of watching cases to their terminations, but are disposed to wander about from one member of the staff to another, from medicine to surgery and so on, by which plan they pick up a good deal of information, but of a somewhat superficial kind.

Dressers and Chinical Clerks.

The compulsory attendance of students as surgical dressers and as clinical clerks affords the only opportunity in our modern scheme of education for that personal training which was the most valuable feature of the apprenticeship system. Although in a large school, where each member of the staff has as many dressers or clerks as he has beds, this personal relation must approach zero; zet in most schools it is a powerful educational influence. So far as possible students should be allowed to choose the member of the staff under whom they are to serve, but there ought to be a limit to the number serving under any one man.

The training received by a dresser or a clinical clerk cannot be over-estimated. He is brought into intimate relation with a considerable number of cases, he is made to observe them closely, to be responsible for recording their history and progress, to take part in their treatment, and to watch their termination. If a proper system of case-taking is insisted upon, he learns to take a broad view of his cases, to care for details, and to appreciate a diagnosis based upon a comprehensive knowledge of a!l the facts. He has abundant opportunities 
for practising methods of examining patients and for becoming expert in many manipulations. The cases he watches are indelibly impressed upon his memory, and form the groundwork of his professional experience. He sees rare diseases, with which in the course of his subsequent practice he will seldom meet, and never under such favourable conditions for study; when he encounters them in later life he will know that but for his hospital experience he would have mistaken or overlooked them.

The system is so good that it should be extended so as to compel all students to serve during the final three years under some member of the medical staff or with an outside practitioner. This would restore the best part of the pupil system. It is possible to learn mach in hospitals, but many things required in private practice cannot be learned there, and the fully-fledged graduate who has received no training outside a hospital makes at first a poor assistant.

RESIDENT Hospitar ApPoINTMENTs.

Under the present system only a small minority can occupy resident hospital appointments, but there are vast storehouses of clinical material in our Poor-law infirmaries which might be utilised for medical education with advantage to those institutions if they would increase the number of resident unpaid assistantships.

Of late years the tendency has been to make these appointments tenable only by qualified men, so that they hardly count at all as means of education for the student before graduation.

\section{The Final Examination.}

The object of medical education should be to turn out welltrained practitioners, but so long as the examinations are fixed by one set of men and the teaching conducted by another, education must be mainly directed to the examination as an end in itself.

Any system of State examinations would only increase and render permanent this evil state of things. It is not quite easy to understand what object the advocates of the oneportal State examination seek to gain. If it were established there would be a tolerably uniform minimum standard examination for England, another for Scotland, and another for Ireland. It is unlikely that differences would not continue to exist between the examinations conducted in London, Edinburgh, and Dublin, and if the centres were multiplied these differences would be more marked, unless it were possible, which it would not be, to employ the same set of examiners all over the country. It is probable that there is no better qualifying examination than that of the English Conjoint Board, but it is doubtful if its standard could be maintained were it the only portal to the profession. If those who advocate a single portal would realise the truth that the standard of sueh a portal must be that of the average student and therefore a low one, we should, perhaps, hear less about the supposed advantages of uniformity.

Constant pressure is exerted by those interested in the teaching of special subjects to increase the range and multiply the subjects of the examinations. There is a demand for more special papers and for specialist examiners which cannot be satisfied with justice to the student. It is quite sufficient to examine in the three great departments of medicine, surgery, and obstetrics. Specialities must be left to post-graduate study, and every encouragement should be given to the development of the movement for providing due facilities for such study.

The paper part of the final examination does not give satisfactory results, as most candidates appear to be unable to write answers to questions in such a way as to do justice to themselves. Doubtless students might do much better if they would practise writing such answers, but it is questionable if the system is a fair one which makes so much depend upon the answers to half a dozen questions upon as many subjects, selected out of such a great field as medicine, for example. In Germany and Austria, and, $I$ believe, in France too, there are no papers in the final examination, which is entirely oral and practical.

It is impossible to defend the very short allowance of time given to the oral and practical parts of the final examination. We may admit that any considerable extension of the tim allowed to each candidats would entirely upset the present system of such an examining body as the English Conjoint Board, which already has as much as it can do to get in all the work that has to be done at the Examination Hall.

Most of the examiners would agree that the present percentage of rejections at the Conjoint Board is too high, but they can only give marks upon the answers they receive. When the unsuccessiul candidates reach nearly 50 per cent., either medical education or the examination must be defective. As the examiners are almost in all cases teachers, they are able to look at this subject from both standpoints, and as an examiner and a teacher myself, I am of opinion that the fault does not lie wholly with the teaching, but that the present examination is nota fair test of the student's knowledge.

Longer oral and practical examinations would involve an addition to the work of the examiners, or an increase in the examining staff, without any prospect of oltaining further funds to defray the extra cost, as the present high fees paid by students could hardly be raised.

The only practical solution of the problem is the multiplication of examining centres. At these local centres the examinations would be conducted by local examiners under the supervision of an assessor or inspector appointed by the qualifying body or by the General Medical Council.

The Conjoint Board already selects many of its examiners from the provinces, and there is no reason to believe that any difficulty would be found in getting suitable men, both able and willing, to devote the necessary time to the examination. As they would not have to deal with large numbers of students, the demand upon their time would not be very great, even if the number of minutes allotted to each student were increased to double that of the present system.

ConcLusion.

I have traversed a good deal of ground-perhaps somewhat superficially - and I have expressed with freedom, but I hope pardónable freedom, a good many opinions which I cannot expect will find universal favour. I have advocated raising the standard of the preliminary examination to that of welleducated boys of 18, abolishing preliminary science, the gradual conversion of systematic lectures into less formal conferences and demonstrations, better organisation of hospital teaching, more exhibition of cases, closer and more constant personal relationship between students and teachers, including under the latter heading outside practitioners, the further development of post-graduate instruction to supply better training in special subjects, longer and more practical examinations, and the multiplication of examining centres.

I believe the changes advocated are not only desirable but inevitable, and that anyone who reads the signs of the times aright will recognise that this is the case.

I have attempted to deal with ordinary medical education and do not presume to suggest that the universities should adopt those limitations which are reasonable in the training of the average man who seeks only a qualification to practise.

In conclusion, permit me to thank you again for the honour of being allowed to address you. I trust I have neither offended nor wearied you, and I beg you to accept my best wishes for the prosperity of your Society and for the success of the session which is inaugurated to-night.

The Antirabic Institute of Rome.-The statistics of the Antirabic Institute of Rome show that in 18g6 of I66 patients treated, 2 died. Both were children who had been severely bitten in a number of places, and who were brought to the institute sixteen days after the infliction of the bites; the disease developed within a fortnight after the course of inoculations. In 1897 , of 212 cases treated, death occurred in $I$; in this case, also, the bites were multiple and deep, and the disease developed on the nineteenth day of treatment. In 1898 , of I I patients treated, 3 died, all during or within fifteen days of the completion of the treatment. From June Ist, 1895, to the end of April, 1899, the total number treated was 630, with a mortality of 0.16 per cent.

We regret to hear that Mr. George Scudamore, the active and public-spirited secretary of the Samaritan Free Hospital and the Marylebone Female Protection. Society, has been compelled to resign both appointments in consequence of prolonged ill-health. 